\title{
Measuring Primitive Reflexes in Children with Learning Disorders
}

\author{
Dr. Sulltane Bilbilaj \\ Dr. Aranit Gjipali
}

Dr. Fatlinda Shkurti

Department of Education, Faculty of Humanities, "Ismail Qemali" Vlora, University

\begin{abstract}
The paper aims to show that the children with learning diabilities have a high level of unconstrained primitive reflexes and that their undeserved suffering also comes from the increased presence of instinctive reflexive movements. This qualitative study is conducted with $20 \%$ of the children with learning disabilities $6-10$ years old,in the city of Vlora,Albania. Also their cognitive development is held "as hostage" by stumbling power of the reflexive movements for the creation of new nerve pathways and schemes. The study is represented by a rich references with contemporary information on the role of primitive neurological reflexes in utero, in the first years of life and the non-integration consequences within their biological time. The study primarily measured the primitive retained reflexes in children in the study. As an instrument for measuring primitive reflexes, the study used "home test" developed by Sally Goddard Blythe. Measurements were made in just eight primitive reflexes based on the work of Petter and Sally Goddard Blythe; Moro, Rooting, Sucking, ATNR, TLR, Handheld, Galant, and STNR. Data were collected from the measurements on the type and percentage of the retained primitive reflexes. It was proven that children with learning disorders have a high level of retained primitive reflexes compared to other children. The findings of this study lead to the need for scientific research to inhibit the primitive reflexes at a young age, but also when they are present beyond their biological age.
\end{abstract}

Keywords: primitive reflexes, retardation, neurological development, learning disabilities,

\section{Introduction}

Learning Disorders refers to a heterogeneous group of problems that appear with obvious difficulties in the ability to understand spoken language, language expression, reading, writing, and mathematical calculations. It is believed that disorders in learning are caused by a mal-function of the central nervous system, which are present from birth and resistant to changesalong the time. They do not depend on the socio-cultural background where the child is part and even from of the way of teaching. During the first two years of primary school, this disorder becomes apparent and therefore their diagnosis is made at the end of this period. During this period, the process of learning in these children results slow and incomplete, compared to their peer group.

Increasing the number of children with difficulties in learning is a problem that requires special attention from the sciences of psychology and pedagogy as well as neurobiology. Central nervous system (CNS)is the control center for thinking, learning and moving. There are many factors that contribute to a person's ability to move well, to speak fluently, to play and to enhace the necessary daily skills to live and learn. The development stages of the SNC are developed in a regular sequence and are the same for all people, egardless of the racial, cultural and geographical influences. The nervous system maturation process begins with primitive reflex movements and continues with complicated brain processes leading to optimal functioning. (Sally Goddard Blythe)

According to the studies so far given data that,brain during developmental phases is vulnerable to developmental disorders that may have different etiologic backgrounds (Teichert, Tomoda, \& Andersen, 2006; Fagiolini, Jensen, \& Champagne 2009; Kolb Gibb , 2011). One of the factors influencing these disorders is the presence of primitive reflexes beyond their biological age as a consequence of their lack of integration in time. (Allen \& Capture, 1986; Zafeiriou, 2004, Sanders \& Gillig, 2011). Also, the primitive unconstrained reflexes are related to certain specific neuropsychiatric disorders (Keshavan 
\& Yeragani, 1987; Youssef \& Waddington, 1988; Zafeiriou, 2004, Links et al, 2010; Nicolson et al, 2011; Sanders \& Gillig, 2011). Studies by Rider 1971, Wilkinson 1994, O'Dell and Cook d Blythe and Hyland in 1997, Bein-Wierzbinski, Goddard Blythe in 2001, Kespwr G in 2003, Taylor M, S Houghton, E Chapman in 2004 Goddard Blythe SA in 2001, 2003, 2005, 2006, 2012, 2013, Agree on the role of primitive reflexes in the child's neurological development and in the learning process.

Also,the movement has a positive impact on the learning process, (Fredericks, Kokot and Krog (2006), but it is emphasized the necessity of considering the content of the motion program in relation to the purpose.It is also noted that there are a number of factors that affect the refraining of primitive reflexes, developmental delays and consequently learning outcomes. (The Institute for Neurophysiological Psychology (INPP) in Chester. Factors are also problems during pregnancy, childbirth, growth and development during the first 12 months of life.

\section{Literature Review}

\subsection{Historical context of studies for primitive reflexes}

Notable from amongst the first pioneers to today's most renowned researchers are: Descartes (1596-1650), Sir Charles Bell (1774-1842) François, MAGENDIE (1783-1855), Sir Charles Scott Sherrington (1857-1952), Rudolf Magnus (18731927), Arnold Lucius Gesell (1880-1961), Temple Fay (1895-1963, Jean Piaget (1896-1980), Lev Semyonovich Vygotsky (1896-1934), Berta Bobath (1907-1991), Glenn Doman (1919-2013), Peter \& Sally Goddard Blythe, Kerstin Linde \& Harald Blomberg, Svetlana Masgutova, Wibke Bein-Wierzbinski

In many studies, indications are found that the unconstrained initial reflexes generally erode, leading to tracks in various limitations and disability (Ayres (1979.1982) Bein-Wierzbinski (2001) Bobath and Bobath (1955), Caputa (1981) DeMyer (1980), Holt (1991), Gazzaniga (1973), Gesell (1947), Blythe (1992), Goddard (1989, 90, 91) Miriam Bender (1976), 0, Dell and (1996) Rosanne Kermoian (1988), Veras (1975) Berne, SA (2006).

In 1970, Gustafson discussed for the first time the presence of the primitive unconstrained reflexes and their effect on the process of learning for children with and without neurological damage. From this study emerged the Moro reflex effect and ATNR STNR in the learning process. In 1972 Rider $B^{1}$, found that children with learning disorders had the presence of reflexes unconstrained significantly compared with normal children.

In 1975, the Institute of Psychology and Neuro-Physiology (INPP) created by Dr. Peter Blythe, along with his student David McGlown, used a variety of methods to assess, train and investigate the role of initial unconstrained reflexes and underdeveloped postural reactions in children with specific problems in the pits.

In 1994, Wilkinson ${ }^{2}$ tested four primitive reflexes with a Wide Range Achievement Test (WRAT). The results showed that the primitive I reflexes were inhibited without an influential factor in learning difficulties and low levels of achievement in all fields. Thus, reflex TLR affects balance and Moro reflex influences on the specific problems of mathematics ${ }^{3}$.

In 1996, Sally Goddard Blythe, director of INPP, created a school based on the program "rating neuromotor, stepping stones to Learn," which examines the history of the evaluation and treatment of primitive reflexes, the importance of primitive reflexes and postural responses in typical and atypical childhood development, searches around neuromotor immaturity and its effect on sensory processing and academic achievement.

In 1997, O'Dell and Cook revealed that Bender exercises based on movements like walking or delay started to crawl, were valuable in stopping hyperactivity.

In 1998 Goddard Blythe and Hyland, examined children who had NDD (Nature Deficit Disorder). Screening was the focus of the primitive unconstrained reflexes which were related to neurological dysfunction of children with learning difficulties ${ }^{4}$. In 2001, Bein-Wierzbinski completed a research project aimed at determining the relationship between the visual system and the primitive reflexes to get into the study and treated half of them with a specific motor program which focused on

\footnotetext{
${ }_{1}^{1}$ (Rider B (1972) Relationship of postural reflexes to learning disabilities. American Journalof Occupational Therapy, 26/5, 239-243) ${ }^{2}$ Wilkinson G (1994) The relationship of primitive postural reflexes to learning difficulty and underachievement ${ }^{3}$ lbid

${ }^{4}$ (Goddard-Blythe \& Hyland (1998) Goddard-Blythe, S. \& Hyland, D. (1998). Screening for neurological dysfunction in the specific learning difficulty child. British Journal of Occupational Therapy, 61, 459-464.) McPhillips, M., Hepper, P.G. \& Mulhern, G. (2000) Effects of replicating primary-reflex movements on specific reading difficulties in children: a randomised, double-blind, controlled trial. Lancet, 355 (9203), pp.537-541.
} 
primitive reflexes and early motor development. Results showed improvement in oculo-motor function and ability of reading, as well as the integration of reflexes'.

In 2001 Goddard Blythe SA - examined the impact of neuro-developmental factors in 54 children who were diagnosed with dyslexia. Participants showed evidence that the reflexes of unconstrained ATNR together and TLR were part of neurodevelopmental factors. In 2002 she described reflexes in the normal development of a child and what happens if some reflexes remain or if some other does not develop. They affect the ability of the child's learning or have an impact on behavior.

In 2003 Kesper G, demonstrated by its ongoing study on the effects of the primitive problems on motor reflexes.

In 2004, Taylor M, S Houghton, Chapman, added that primitive reflexes appear to be related to the concentration of attention disorders, ADHD, developmental Genesis-class failure22. Also in 2004 McPhillips, M. Sheehy, N. has data on the presence of the primitive unconstrained reflexes and motor problems in children with reading difficulties ${ }^{3}$.

Goddard Blythe SA (2005) studied the relationship between the unconstrained reflexes and reading problems, as well as the efficiency of INPP program for several schools in Northumberland ${ }^{4}$. Sally Goddard (2006) brought evidence that failure to integrate the primitive reflexes can lead to neuro-developmental delays which leads to considerable immaturity of the nervous system function. In 2006 in the book: "The well balanced child" the emphasis is placed upon the importance of the whole body involvement in the learning process. Through movement, the brain reached maturity. This edition includes a new chapter with movement exercises that parents can use at home, so that their children fulfil their potential. Berne, S.A. (2006) provides information on the treatment of primitive reflexes in babies and children In order to anticipate disturbances ${ }^{5}$.

The Conference on the 40th anniversary of INPP, directed by Petter and Sally Goddard Blythe, held in London in October 2015, noted the successful implementation of INPP Program for curbing primitive reflexes in several different countries. For the first time research of INPP was attached to the findings of this study.

\subsection{General knowledge of primitive reflexes}

During the development of the fetus ${ }^{6}$, a set of reflexes is formed, which are called primitive reflexes ${ }^{7}$ and in utero are one of the first forms of movement ${ }^{8}$. They are involuntary stereotyped movements that respond to special stimuli and are the dominant form of movements during the last months before and after the first months of birth ${ }^{9}$. Early life periods are very important, due to two types of movements, Primitive reflexes and stereotypes ${ }^{10}$. Primitive reflexive movements and stereotypes are very important in the development process.

Primitive reflexes should be present at birth and are an indicator of the state of the central nervous system ${ }^{11}$. Reflexive movements are the first foundations of the nervous system. Very early in the uterus, reflexes and primitive movements help the brain's development ${ }^{12}$. Most of the primitive reflexes do not last beyond the first year, but they have to be slowed down during this year ${ }^{13}$.

\footnotetext{
1 (Bein-Wierzbinski, W. (2001). Persistent primitive reflexes in elementary school children. Effect on oculo-motor and visual perception. Paper presented at The 13th European Conference of Neuro-Developmental Delay in Children with Specific Learning Difficulties. Chester. UK.)

2 Vol.19/1, International Journal of Special Education. Vol.19/1: 23-37.

${ }^{3}$ Dyslexia. 14/4: 316-338.

${ }^{4}$ (Goddard Blythe, S.A. (2005). Releasing educational potential through movement. A summary of individual studies carried out using the INPP Test Battery and Developmental Exercise Programme for use in Schools with Children with Special Needs. Child Care in Practice. 11/4:415-432.)

${ }^{5}$ The primitive reflexes: Treatment considerations in the infant. Optometry and Vision Development:37(3):139-145 McPhillips, M. \& Jordan-Black, J.A. (2007) Primary reflex persistence in children with reading difficulties (dyslexia): a cross-sectional study. Neuropsychologia, 45 (4), pp.748-754.

${ }^{6}$ (Goddard-Blythe and Hyland (1998)

${ }^{7}$ Hannanaford (1995)

${ }^{8}$ Goddard-Blythe and Hyland (1998).

${ }^{9}$ Continuity of neural Functions from Prenatal to Postural Life Fetal. Motolity in the first helf of pregnancy. P.46-64.
} ${ }^{10}$ Reinhard Rohkamm, M.D. Color Atlas of Neurology. (2004) Normal and Abnormal Function of the Nervous System. Reflexes. p. 4060.

${ }^{11}$ (Wolf \& Binet.1973)

12Clara Hannanaford, PH.D. Smart Movement. (1995), p. 96-107.

13Zafeiriou, (2004). 
Primitive reflexes ${ }^{1}$ are stereotypical ${ }^{2}$, automatic movements, driven by the cerebral trunk and do not require cortical involvement. They are needed for survival and development in the utero as well as in the early months of life.

While the most sophisticated brain centers begin to mature, the primitive reflexes turn into an obstacle and need to vanish, so that the brain develops neurologically in the right way, which is needed for its development ${ }^{3}$.

Primitive reflexes cannot be restrained, but some of them integrate into new, voluntary movements as a lifelong reflection ${ }^{4}$. Movements form neural networking patterns that allow the connection of different brain areas and are very important for the learning process ${ }^{5}$, communication behaviors, emotional and feel-good relationships, and motivation 6 in later life.

A human being is born with very little voluntary will and limited mobility. Reflexes help in the process of delivery and are needed for early baby development. They are mainly used for protection, nutrition or survival? .

Usually appearing during conception, pregnancy or birth, primitive reflexes stay for a short period of time until leaving the postural reflexes ${ }^{8}$. During the first year of life, these reflexes curb and mature in the most sophisticated brain areas. Once the central nervous system matures and the reflex has completed its work, it must undergo retardation or transformation into a higher part of the brain ${ }^{9}$.

Postural reflexes, which are the foundation for later voluntary movements ${ }^{10}$, should be used by the baby to cope with the requirements of a gravity-based environment and provide the basis for controlling equilibrium, behavior, and voluntary movements ${ }^{11}$. If there is a group of primitive unconstrained reflexes, the central nervous system will not function properly ${ }^{12}$. Each reflex is accompanied by one or more Sensory Processing Systems ${ }^{13}$ : listening, tasting, touching, smelling, sighting, space orientation, perception.

Therefore, if the primitive reflexes are not retained, a child or person may experience dysfunction of one or some of the sensory processing systems. This leads us to what is called "Sensory Processing Disorder".

All areas of mal-function of sensory processing systems are related to the development of the nervous system: vision dyslexia, cortical - poor attention, vestibular - poor coordination, vestibular - loss of balance, lips and mouth - pronounced and poor speech.

Incomplete integration of primitive reflexes may be a cause for ADD and ADHD, autism, developmental slowdown, sensory disorders of socialization, vision, hearing, behavioral disorders and extreme fear, lack of self-confidence, difficulty in learning ${ }^{14}$, laborious efforts to make the odds and the constant feeling of confusion. Rhythmic movements help the children to finish the original reflex models and transform the challenges ahead.

Postural reflexes are related to the development of later voluntary movements. Postural reflexes are the basis of future movements, initiated by the stimulation of high brain centers ${ }^{15}$.

${ }^{1}$ McPhillips et al., (2000),

${ }^{2}$ (Guyton, 1991; Thelen \& Fisher,1983)

3 (Rohkamm 2004; Melillo, 2009)

4 (Gold, 1997; Wilkinson, 1994).

5 (McPhillips et al.2000, Goddard Blythe 2001, McPhillips and Sheehy 2004, Taylor et al. 2004, Goddard Blythe 2005)

${ }_{6}^{6}$ (McPhillips et al.2000, Goddard Blythe 2001, McPhillips and Sheehy 2004, Taylor et al. 2004, Goddard Blythe 2005)

${ }^{7}$ Rohkamm, M.D. Color Atlas of Neurology. (2004), p. 26.

8(APA, 2000; Goddard, 1996; Hocking 1997; McGoey, Eckert \& DuPaul, 2002; Taylor, 1998, 2002 , Gold, 1997; Wilkinson, 1994).

${ }^{9}$ Capute, A. J, Palmer, F. B., Shapiro, B. K, Wachtël, R. C, Ross, A, Accardo, P. J. (1982), Primitive reflex profile: A quantitation of

primitive reflexes in infancy. Developmental Medicine and Child Neurology, 26, p. 375-383.

${ }^{10}$ (Gold, 1997; Wilkinson, 1994)

11Wolf, Theta. Alfred Binët. Chicago: University of Chicago Press, (1973). BIRTH. 52-62Transition from Reflex Movement to Voluntary

Movement. p. 279-282.

${ }^{12}$ (Salkind, 2002)

13(Goddard, 1996) Reinhard Rohkamm, M.D. Color Atlas of Neurology. Reflexes. p. 40.

${ }^{14}$ (McPhillips et al.2000, Goddard Blythe 2001, McPhillips and Sheehy 2004, Taylor et al. 2004, Goddard Blythe 2005)

${ }_{15}$ (Zafeiriou Di. Primitive reflexes and postural reactions in the neurodevelopmental examination. Pediatr Neurol 2004; 31:1-8.) 
Reflexes provide a form of practice that later harmonizes in a voluntary movement ${ }^{1}$. It is difficult to determine the number of reflexes, because the terminology used to describe a reflex is similar or insufficient information is available for them.

Popular opinion cites are about 70 primitive reflexes (Illingworth, 1987). Almost all the researchers used the same method of examining and determining the location of the reflexes, showing the validity of the method used.

\subsection{Consequences of non-refraction of primitive reflexes}

If primitive reflexes are maintained beyond the normal age of integration, they may lead to difficulty in learning, socializing, academic success, hormonal balance, motor control etc. ${ }^{2}$. In essence, the perception of the internal and external environment and the responses to it may be irregular, so even conscious life can be disrupted.

Children with learning disabilities ${ }^{3}$ and other various types of nerve development are known to preserve the primitive reflexes, which have contributed to their symptoms and the level of dysfunction.

Each reflex is linked to one or more of the sensory processing systems: space, taste, touch, smell, visibility, hearing, proprioceptive and / or interoceptive 4 .

Therefore, if the primitive reflex is maintained, a child may experience dysfunction within one or some of the sensory processing systems. This can lead to what is known as a sensory disorder.

Each reflex plays a special role in behavior and learning, but when an immature neuro-motor is present in a school-age child, some reflexes are included before the symptoms begin to appear in the classroom. The Asymmetric Tonic Reflection (ATNR) emerges with the rotation of the head from each side, which leads to the extension of the arm, the hand and the foot by turning the head and the bending of the opposite limbs. If the ATNR remains active in the school-age child, it affects the vertical equilibrium control, because the head reversal causes the arm and leg to extend from one side of the body, while the opposite limbs bend, breaking the balance control. It also affects arm and hand control when the head is turned on one hand, handwriting during writing, and the visual skills needed to read.

While ATNR affects the muscular tone of the two sides of the body, another reflex, STNR, affects the joint function of the upper and lower body parts. It appears in the fourth month of life, when the baby is about to crawl on the ground with his toes and hands and should be restrained in months 9-11. The head bend makes the arms bend and the legs stretch out. Conversely, the spread of the head leads to the extension of the arms and the bending of the legs.

If STNR is not integrated with a school-aged child, it affects the body's attitude during sitting or sitting, the ability to stay motionless in one place, the muscle tone and the necessary coordination for activities such as swimming lessons and in confined areas. Other studies have produced, in duplicate, a link between non-reconstructed STNR (ADN) and (ADHD) and problems related to speed and accuracy. The unplanned primitive reflexes also influence the proper holding of the head in relation to the body position. This affects not only the balance of the body but also the control of eye movements. It also affects writing, reading, copying, and space co-ordination.

An active reflex, such as the Asymmetric Tonic Neck Reflex (ATNR) reflection, may, among other things, make it harder for the body and eyes to work together and cause problems with the eyes or hands. This can cause reading difficulties, including the concentration of eyes at the same point (convergence problems). An active ATNR can also complicate writing, causing trouble because of pulling control and passing to the center line.

A reflex which is often active in dyslexic children is the Symmetrical Thick Tone Reflex (STNR). The non-regressed STNR gives problems with accommodation, so the ability to move the eyes closely. Children with unsteady STNR often develop tunnel-vision, have convergence problems, and experience eye strain when they read. While ATNR, STNR and head restraints are examples of reflexes that work with the equilibrium mechanism; responses to the touch stimulant have an

${ }_{1}^{1}$ (Reinhard Rohkamm, M.D. 2004, Color Atlas of Neurology. Voluntary Movements. P.42-45).

2(DSM-IV Clsification. Learning Disorder. p.51-79)

${ }_{3}^{3}$ (Edited by Neil J. Salkind. Child Development .p. 235-244, ADHD Greene, R.W., Beszterczey, S.K., Katzenstein, T., Park, K., \& Goring, J. (2002). (Journal of Emotional and Behavioural Disorders, 10, 79-90. , spektrit të autizmit Edited by Neil J. Salkind. Child Development .p 261-265,)

${ }_{4}^{4}$ (Goddard, 1996) Reinhard Rohkamm, M.D. Color Atlas of Neurology. Reflexes. P. 40.) 
impact on learning. Palmar Reflex is such an example. If one touches the palm of a newborn baby's hand, the baby's fingers lock up tightly around one's finger.

A residual Palmar Reflex left over after the first months of life affects the development of the large thumb finger and the opposite finger movements needed for the individual operation of each finger. This affects handwriting and sometimes relates to speech problems.

Most children with autism have different sensory disorders. Many of them have a problem with eyesight, interaction with others, communication, listening etc. An active Moro reflex can result in children becoming overweight. These children are confused and tired quickly, especially in noisy environments, where they can react by becoming hyperactive and disruptive, or, alternatively, lock themselves out from stimuli.

\section{Methodology}

\subsection{Brief description of methodology}

The purpose of the methodology is to help us understand, in the best possible way, not the research products, but the process itself 1 . This study is a qualitative study aimed primarily at the presence of primitive reflexes in children with learning disabilities aged 6-10 years.

Fourteen children with learning disabilities studied have been diagnosed by the doctor with: Autism Spectrum Disorders, Injury Disorders (ADHD, ADD, HD), Communication Disorders, and Sensory Integral Disorders.

The lack of theoretical and practical information on this field of study in Albanian pedagogy makes the realization of accuracy of each step of the study more necessary. In order to realize the purpose of the study, there is also an important role in uncovering the immateriality of the SNQ and measuring the primitive irreversible reflexes in children with learning disabilities as a necessity of qualitative study. Based on the level of conservation of the primitive inflexible reflexes, derived from the measurements of the children taken in the study, interference can be developed based on the type of primitive reflexes.

\subsection{Research Questions} children?

Is there a higher level of primitive unconstrained reflexes to children with learning disabilities compared to other

\subsection{The hypothesis of the work}

Hypothesis: Children with learning disabilities have a high level of learning primitive unconstrained reflexes..

\subsection{Selection of samples}

The population of the study makes up of a group of 14 students with learning disabilities, 12 boys and 2 girls, 9 -year public and non-public schools in Vlora. The sample was selected through a selective method, taking a non-casual representative sample. Students taken in this study are those who have finished first grade or second grade of elementary school.All children are diagnosed by a neuropsychiatrist, mainly from the diagnosis center in Tirana, and a child has been diagnosed in Italy.

The criterion for carrying out the study was that this target group of children be diagnosed by a physician with learning disabilities. Forms of learning disorder based on the Doctor's Standard Assessment were:

- 8 of the children or $57.1 \%$ are with Autism Spectrum Disorders,

- while 6 other children are diagnosed with dyslexia, ADHD and communication disorders

During the study, some children have more than one disorder, for example, except for children with autism spectrum disorder, they may also have hyperactivity or disturbance disorders.

\footnotetext{
${ }^{1}$ (Cohen, Manion \& Morrison, 2000: 45)
} 


\subsection{Instruments to study implementation}

The study was conducted on the basis of qualitative methodology. Qualitative method was conducted through structured interviews with the parents of the children studied and the test for the measurement of the primitive reflexes, compiled by Sally Goddard Blythe.

\subsection{Structured questions of an interview}

As mentioned above, structured questions of an interview were drafted by Sally Goddard Blythe for the purpose of studying the subject on primitive reflexes and structured in a well thought-out way to gather all the necessary data for the study. From structured questions of an interview the study expected to come up with data for further investigation by a specialist doctor to highlight neuromotoral immaturity and immature Central Nervous System due to the presence of untreated primitive reflexes in children ages 6-10.

In the first column, structured questions are about some actions such as:

- walking foot in hand at age 4-9 months,

- sucking the thumb after the age of 5 ,

- urinating on the bed,

- when the child started to talk or walk,

- has vomiting from travel (travel sickness),

- use of fingers to fasten or break down the buttons,

- dominant hand,

- allergies,

- sense of self,

- morbidity,

- language position when eating or writing, and many other signs.

In the second column, structured questions are about some actions such as:

- it is difficult to ride a bicycle

- in the capture of the ball,

- in writing with overwhelming lettering or irregular writing

- overwhelming noise

- discontent

- makes a lot of mistakes when copying from the board

All of the above and many others are the product of refractory reflexes.

\subsection{The test for measuring the primitive reflexes "Home Test"}

Like the structured questions of an interview, the "Test at home"1 test was also drafted and drawn up by Sally Goddard Blythe. The tests were taken from "Attention, Balance and Coordination²: The ABCs of Learning Success" by Sally Goddard Blythe (2009) and "Primitive Reflex Training3; Visual Dynamix "by Lori Moybray (2010) - accompanied by a series of corrective exercises for compiled reflexes. This type of test is used to detect the type of reflex and the percentage of its stored level. This is a collection of tests designed to show the presence of untreated neonatal reflexes. Tests contain exercises that show the probability of reflexes stored in infants and older children. If these reflexes are stored then the child can give warning signs in daily activities. Special attention is required to observe many signs of difficulty to understand that the child is not failing because of lack of will, but as a result of lack of communication between the brain and the body.

The test is only for the eight reflexes selected in the study, despite the proper practice to detect the type of reflex and their level of conservation. Reflex type indicators are lighter because they are merely specific movements, such as if

1 http://www.retainedneonatalreflexes.com.au/test-at-hom/

2 Sally Goddard Blythe (2009) 'Attention, Balance and Coordination: the ABC's of learning success'

${ }^{3}$ Lori Moybray (2010) 'Primitive Reflex Training; Visual Dynamix 
the child cannot walk with the feet of the ankle open and the arms open and straight, but makes the body bend forward when it is required to walk. This is an indication that the baby still continues with Moro's reflex.

The evaluation of how many percent of the reflection is retained is given for each type of reflex, but with the pro bability of having errors of the measuring instrument itself. In the case of this study, the percentage measurement may be greater or smaller than the real value, so we say we have random errors.

We are taking an example of the TLR reflex rating and seeing the casual error: In the test, the child lies down on the floor with the belly in the position as a landowner with a hand and foot raised from the ground at the same time. The difficulty lies in holding hands and feet raised from the floor and straight without reversal. In the event that the child cannot perform this exercise, but the legs are not held right but they are reversed, the ankle angle and the lack of lifting indicate the presence of the reflex. The percentage rating is expressed by $0 \%, 25 \%, 50 \%, 75 \%$ and $100 \%$.

\subsection{Data processing}

In the case of variables in the study, the table method of their presentation was first used. Along the tables, graphic data was used for bar graphs where the nature of our data favored the use of this technique (suitable for visualization of categorical data). Also, graphics were used in pie charts.

All statistical data analysis was performed with Statistical Analysis System (SAS), version 9.1.

\section{Structured Interviews and Their Analysis}

\subsection{Collection of information from structured interviews}

After defining the disciplinary orientation and design for qualitative study, the researcher gathered information on the core study question as to whether they are a high level of primitive reflexes in children with learning disabilities compared to other children.

According to the implementation of the individual INPP program, to which we refer, the answers were first gathered from the structured questions of an interview received by the parents and then directed to the specialist neuropsychologist for evaluation of the primitive reflexes, the type of reflex, the underlying cause, and the level of its preservation. Structured interviews represent a common form of data collection for a qualitative study.

\section{Using structured questions of an interview with parents to see if children with learning disabilities have unprecedented primitive reflexes.}

Despite the small number of children involved in the study, at this stage we tried to interpret the answers of the parents to the structured questions of the children surveyed. If some or all of the answers are positive, then there is a need for further investigation by a specialist physician to evaluate the primitive reflexes, in order to reveal an immature Central Nervous System, indicating a refraction of the primitive reflexes.

The questions are about:

- early childhood

- child health performance

- achievements in different teaching and classroom attitudes.

\subsection{Analysis of the findings of 14 structured interviews}

- In $29 \%$ of cases, they held their finger in the mouth or walked with their fingertips ( $7 \%$ always and $22 \%$ sometimes); this sign indicates the presence of the Galant and TLR filament.

- $21.4 \%$ of cases have often or always contracted serious miscellaneous diseases during the first 18 months of life, a sign indicating the presence of the uninhibited primitive reflex ATNR and Moro.

- $50 \%$ of children during the first years of life have had difficulty in passing food; do not correctly chew the food using jaw movement to break the food. Likewise, $22 \%$ of cases have had problems with feeding up to 3 months old, signs indicating the presence of the primitive reflexes of suction, research, STNR, Palmar and TLR.

- In 8 cases or $57 \%$ of them, it is stated that their child during the first 6 months of life has shown signs of irritation, signs that allow for primitive unbridled reflexes such as Moro and Galant 
- $\quad 35.71 \%$ of parents say their child has often experienced high temperature and $35.71 \%$ of them sometimes.

- $50 \%$ of parents say their child has urinated in bed after age five, always, sometimes or sometimes, and this sign indicates the presence of the spinal reflex.

- $29 \%$ of the cases have had problems during travel (vomiting during travel), signs that indicate the spring of the TLR primitive reflex.

- $21.4 \%$ of children have always, often or sometimes suffered from ear infection signs indicating the presence of the original Moro reflex.

- $21 \%$ of children have had allergies frequently or sometimes and in one case often suffer from asthma, a sign indicating the presence of Moro reflex.

- $60 \%$ of children have chronic signs of digestive disorders that indicate the presence of Reflex Moro and Galant.

- In $64 \%$ of cases, the child has not experienced the "walking scale" of the walking foot, or the prolonged phase of the STNR reflex.

- $71.4 \%$ of cases have been delayed in speech; a sign that indicates the presence of the initial Palmar, TLR, suction and search reflex.

- $57 \%$ of children do not look directly at the eye when talking to someone, a sign that indicates the presence of the reflexes ATNR, TLR, and STNR.

- $50 \%$ of children have problems, often with the identification of the left or right hand and it is confirmed that $86 \%$ of them have often had problems with the identification of the dominant hand that indicates the possibility of refraction of the original ATNR reflex, Suction.

- $86 \%$ of children always have difficulty tying shoelaces or fastening clothing or buttons, which shows the presence of the Palmar and suckling reflexes.

- $79 \%$ of cases have had a problem with reading and writing in kindergarten or school, $36 \%$ of children have been identified or overwhelmed, $93 \%$ of them have often had difficulty writing or writing irregularly. All of these signs indicate the presence of the Moro, suction, ATNR, Palmar, Plug and STN reflexes.

- $36 \%$ of children make many mistakes when copying from the board at all times or frequently and is indicative of the presence of primitive reflexes STNR and ATNR.

- $\quad 43 \%$ of children always have difficulty in catching the ball and in poor eye-hand coordination and $29 \%$ of them sometimes, this is the result of non-refraction of the original ATNR reflexes. Moro, Palmar and STNR.

- $\quad 43 \%$ of children always or often have difficulty or sluggishness in PE (physical education), dance, gymnastics; and $28 \%$ sometimes; this indicates the presence of the original reflexes Moro, TLR, ATNR, and STNR.

- $50 \%$ of children have difficulty riding bicycles and swimming, this indicates the presence of STNR and TLR reflex.

- $57 \%$ of children have always had difficulty with speaking and articulation, and in $36 \%$ sometimes; demonstrating the presence of the primitive reflexes of suffocation and unbridled research.

- In $50 \%$ of cases children have had chest colds or immune problems; always or sometimes indicative of the refraction of the Moro reflex.

- In $64 \%$ of cases the child hold a pencil strangely, a disorder that indicates the presence of the primitive Palmar and suckling reflex.

- $64 \%$ of cases children overwhelm to unexpected noises at all times or often and this indicates the presence of the original reflex.

- $\quad 36 \%$ of children pretend to have ants inside their pants, often or always, and are signs of the unstoppable rifles, Moro, TLR and Galant.

\section{Measuring Initial Reflections and Their Analysis}

\subsection{Analysis of the findings of primitive reflex measurements}

Data was collected from the measurement for primitive reflexes in general, on their presence or absence, as well as the level of conservation. The test focused on the 8 main primitive reflexes, which are even more dominant in the disorders that occur among the children surveyed:

For the successful completion of the test, we rely mainly on contemporary literature, but also on world experiences received from different countries, which had the appropriate guidelines on how to achieve them. These guidelines are structured in such a way that parents or field specialists have the opportunity to evaluate the presence of primitive reflexes, emphasizing the fact that this is worthless in the perspective of a study but also in the daily practice in the family or in the 
diagnostic centers. Initially, the frequencies and percentages of the type of disorder are given. Table No.1 clarifies the types of disorders that children in the experiment group present.

Table 5.1. Pupils by type of learning disorder

$\begin{array}{lll}\text { Type of disorder } & \text { Frequency } & \text { Percentage } \\ \text { Autism } & 8 & 57.1 \% \\ \text { Dyslexia } & 2 & 14.3 \% \\ \text { ADHD } & 2 & 14.3 \% \\ \text { Oral disorder } & 2 & 14.3 \% \\ \text { Total } & 14 & 100.0 \%\end{array}$

Based on the above data, it can be seen that out of the 14 children of this group, 8 children, or $57.1 \%$ of them with learning disorder and with Autism Spectrum Disorders, and for the rest these disorders are mainly related to dyslexic disorders, $A D H D$ and Linguistic disorders, respectively from 2 children or $14.3 \%$ of these cases.

\subsection{Measurement for the type of positive primitive reflex to 14 children taken in the study}

Measurement of reflexes for all children studied with a positive outcome (deviation above 0 ) does not indicate the type of autism disorder, dyslexia, hyperactivity, oral disorders, etc., but only presents the fact that these children with learning disorder and presence Added to the primitive reflexes.

Table 5.2 .1. Type of Primitive Reflexes Positive to Children Taken in the Study.

\begin{tabular}{|c|c|c|}
\hline Result of Positive Primitive Reflexes & Frequency $\%$ & Percentage \\
\hline Asymmetric Tonic Neck Reflex (ATNR) & 14 & $100.0 \%$ \\
\hline Tonic Lateral Reflex (TLR) & 14 & $100.0 \%$ \\
\hline Symmetrical Tone Neck Reflex (STNR) & 14 & $100.0 \%$ \\
\hline Spinal Galant Reflex & 9 & $64.2 \%$ \\
\hline Moro Reflex & 13 & $92.8 \%$ \\
\hline Rooting Reflex & 9 & $64.2 \%$ \\
\hline Sucking Reflex & 8 & $57.1 \%$ \\
\hline Palmar Reflex & 9 & $64.2 \%$ \\
\hline
\end{tabular}

According to the data in Table 1, the primitive reflexes: Asymmetric Tonic Neck Reflex (ATNR), Tonic Labyrinthine Reflex (TLR) and Symmetrical Tonic Neck Reflex (STNR) are observed in all children studied or otherwise reported in $100 \%$ of cases studied. Reflex Spinal Galant, Rooting Reflex and Palmar Reflex are reflected in 9 children or $64.2 \%$ of them. Moro Reflex was also observed in 13 children or $92.8 \%$, while Sucking Reflex was reflected only in 8 children, accounting for $57.1 \%$ of their total number.

\subsection{Percentage of primitive reflexes for each child}

Table above provides specific data on the percentage of primitive reflexes retained for each child. For example: child 1 retains 4 retained primitive reflexes and has overlapping reflexes such as ATNR, TLR, STNR and Moro according to the percentages specified in the table. This is studied and measured for each of the 14 children.

Table 5.3. Percentage of Primitive Reflexes for Each Child.

\begin{tabular}{|c|c|c|c|c|c|c|c|c|}
\hline Child & ATNR & TLR & STINR & MORO & GALAN & $\begin{array}{l}\text { ROOTIN } \\
\text { G }\end{array}$ & SUCKIN & PALMAR \\
\hline 1 & $100 \%$ & $75 \%$ & $50 \%$ & $25 \%$ & $0 \%$ & $0 \%$ & $0 \%$ & $0 \%$ \\
\hline
\end{tabular}




\begin{tabular}{|c|c|c|c|c|c|c|c|c|}
\hline 2 & $100 \%$ & $25 \%$ & $25 \%$ & $0 \%$ & $25 \%$ & $75 \%$ & $75 \%$ & $50 \%$ \\
\hline 3 & $100 \%$ & $75 \%$ & $75 \%$ & $25 \%$ & $25 \%$ & $100 \%$ & $100 \%$ & $75 \%$ \\
\hline 4 & $75 \%$ & $75 \%$ & $50 \%$ & $50 \%$ & $0 \%$ & $75 \%$ & $50 \%$ & $25 \%$ \\
\hline 5 & $75 \%$ & $50 \%$ & $25 \%$ & $25 \%$ & $25 \%$ & $0 \%$ & $0 \%$ & $0 \%$ \\
\hline 6 & $75 \%$ & $75 \%$ & $25 \%$ & $50 \%$ & $25 \%$ & $25 \%$ & $0 \%$ & $25 \%$ \\
\hline 7 & $75 \%$ & $100 \%$ & $75 \%$ & $25 \%$ & $0 \%$ & $50 \%$ & $50 \%$ & $25 \%$ \\
\hline 8 & $50 \%$ & $25 \%$ & $25 \%$ & $25 \%$ & $0 \%$ & $25 \%$ & $25 \%$ & $25 \%$ \\
\hline 9 & $75 \%$ & $25 \%$ & $25 \%$ & $25 \%$ & $25 \%$ & $75 \%$ & $75 \%$ & $25 \%$ \\
\hline 10 & $100 \%$ & $25 \%$ & $75 \%$ & $25 \%$ & $25 \%$ & $100 \%$ & $100 \%$ & $75 \%$ \\
\hline 11 & $75 \%$ & $75 \%$ & $50 \%$ & $50 \%$ & $25 \%$ & $0 \%$ & $0 \%$ & $0 \%$ \\
\hline 12 & $50 \%$ & $25 \%$ & $25 \%$ & $25 \%$ & $0 \%$ & $0 \%$ & $0 \%$ & $0 \%$ \\
\hline 13 & $75 \%$ & $25 \%$ & $25 \%$ & $50 \%$ & $75 \%$ & $25 \%$ & $25 \%$ & $25 \%$ \\
\hline 14 & $50 \%$ & $25 \%$ & $25 \%$ & $25 \%$ & $25 \%$ & $0 \%$ & $0 \%$ & $0 \%$ \\
\hline
\end{tabular}

\section{Discussion of Results}

The study aimed to show that children with learning disabilities have a high level of retained primitive reflexes.

\section{The hypothesis of the study was:}

Children with learning disabilities have a high level of retained primitive reflexes.

The quantitative and qualitative results are consistent with each other by proving the hypothesis $\mathrm{H} 1$ : Children with learning disabilities have a high level of retained primitive reflexes.

According to the data we have that primitive reflexes: Asymmetric Tonic Neck Reflex (ATNR), TLR (Tonic Labyrinthine

Reflex) and Symmetrical Tonic Neck Reflex (STNR) are observed in all children studied or otherwise reported in $100 \%$ of cases Studied. Reflex Spinal Galant, Reflection of Reflection and Reflection of Reflex are reflected in 9 children or $64.2 \%$ of them. Moro reflex was also observed in 13 children or $92.8 \%$, while Reflex suction was reflected in 8 children, accounting for $57.1 \%$ of their total number.

Also, from the analysis of structured questions, there is a high presence of primitive reflections in these children. Thus, for $29 \%$ of parents, their parents say that their child has held his finger in his mouth or has gone to bed Fingers ( $7 \%$ always and $22 \%$ ever); this sign indicates the presence of Spinal Galant and TLR.

In 3 cases or $21.4 \%$, the child has undergone various serious illnesses during the first 18 months of life. This sign indicates the possibility of the original unrestrained reflex ATNR and Moro.

Also, $50 \%$ of cases during the first years of life, the child has had difficulty in passing food. Likewise, $22 \%$ of cases, these children have had problems with nutrition up to 3 months of age; these signs of nutrition indicate the presence of the primitive reflexes of Sucking, Rooting, STNR, Palmar and TLR. In 8 cases or $57 \%$ of them the child during the first 6 months of life has shown signs of irritation, signs that allow for unforeseen primitive reflexes such as Moro and Galant, $71 \%$ of cases, the child has often or sometimes high temperature, $50 \%$ of parents say their child has ever urinated in bed after age five, often or sometimes, and this sign indicates the presence of the Galant reflex. In $21 \%$ of allergies, $60 \%$ showed chronic digestive disorders, signs showing the presence of Moro and Galant reflexes.

In $64 \%$ of cases, the crawl movement never happened, or it has happened very rarely, a sign that relies on the primitive STNR reflex.

In $71.4 \%$ of cases there was speech delay, a sign indicating the presence of the primitive Palmar, TLR, Sucking and Searching reflex,

In $57 \%$ of cases the child does not look into the eye, a sign indicating the presence of the reflexes ATNR, TLR and STNR. $50 \%$ have had problems with left or right hand identification and it is confirmed that $86 \%$ of them have had frequent problems 
with dominant hand identification, which indicates the possibility of moistening the original ATNR Reflection, Research and Suction Reflection. In all cases (100\%), children have always experienced problems with the sitting and still standing, as well as the concentration of attention, signs that indicate the presence of the Moro and Galant reflexes .

In 12 cases, or $86 \%$ have had difficulty tying shoelaces or dressing themselves; showing the presence of the Palmar and suckling reflexes.

In $79 \%$ of cases children have had problems with reading and writing, in kindergarten or school, always or often. 5 children, or $36 \%$ of children, have been identified to not recognize the characters or write them backwards. Similarly, 13 children or $93 \%$ of them have often had difficulty writing or writing irregularly. All of these signs indicate the possibility of the existence of retained primitive reflexes, oro, Sucking, ATNR, Palmar, Babinski and STNR.

In $36 \%$ of cases, the child makes multiple mistakes when copying from the board. This is indicative of the presence of unbridled primitive reflexes, STNR and ATNR.

In $43 \%$ of the sample, children always have trouble catching the ball and in poor eye-hand coordination, $29 \%$ of them never. Difficulty in catching the ball, as well as eye-hand coordination, may be due to the refraction of the original ATNR reflexes. Moro, Palmar and STNR. 43\% of parents confirm that their child has difficulty or sluggishness in physical education, dancing, and aerobics. These difficulties point to the presence of Moro, TLR, ATNR and STNR reflexes.

Regarding the child's difficulty in running bicycles or swimming, about $50 \%$ of children have experienced these difficulties; this indicates STNR and TLR reflex.

Likewise, in $57 \%$ of cases, children have always had difficulty speaking and articulation, in $36 \%$ action that enables the presence of retained reflexes, Sucing and Searching. In $50 \%$ of cases, children have had chest colds or immune problems ever or sometimes, which is indicative of the refraction of the Moro reflex.

In $64 \%$ of cases, mothers noted that the child holds a pencil in a strange manner -this indicates the presence of the primitive Palmar and Suckling reflex.

In $64 \%$ of cases it is noticed that children overwhelm to unexpected noises, this opens up the opportunity for the primitive retained reflex, Moro.

In $36 \%$ of cases, the child looks like ants inside the pants, these are signs of unrestrainedporimitive reflexes, Moro, TLR and Galant.

\section{Conclusions and Recommendations}

From this qualitative study we can draw some conclusions that are worthwhile to attract the attention of all stakeholders, who are able to use and who are engaged in building political interference to these disorders.

\subsection{Conclusions}

1. There was a correlation between maintaining primitive reflexes and learning disorder.

2. Children with learning disabilities have a high level of primitive retained reflexes compared to other children.

3. Undeserved difficulties and suffering of children with learning disabilities come from the increased presence of instinctive movements.

4. Their cognitive development is held "as hostage" by stumbling power of the reflexive movements for the creation of new nerve pathways and schemes.

5. Children who have retained primitive reflexes have low school achievement and various concentration and behavior problems.

6. All children have unwanted reflexes regardless of the type of disorder that they carry: autism, hyperactivity, dyslexia, or disruption of communication.

7. All children saw an overlap of the primitive reflexes with two or more reflexes.

8. The data from the parents' interviews were almost the same as neuropsychiatric data from the measurement of primitive reflexes.

9. There is a lack of theoretical and practical information from the family and the school about primitive reflexes, about their role in the life of the individual. 


\subsection{Recommendations}

\section{Tips for integrating primitive reflexes}

1.Provide the family (young parents), programs and theories for the integration of primitive reflexes, their emerging lifetime role through TV shows or counseling Centers for Pregnant Women and Consultants during the follow-up Baby to prevent the disorder.

2. To require training by experts who have developed integration programs and theories of primitive reflexes..

3. To train teachers and parents of children with disabilities, how they themselves understand and evaluate the presence of retained primitive reflexes.

4. Establish evaluation commissions for neuromotor maturity in all children in schools, especially with children of the first grade.

5. Establish centers for the treatment of children with learning disabilities in each school and training by genuine specialists for unforeseen reflexes.

6. Establish a plan so that work with primitive reflections works according to advanced methods and practices already ested in developed countries.

7. Choose a plan that fits the needs of the child and the family.

\section{Some training opportunities:}

- Institutes for Human Potential, https://iahp.org/contact-info

- Kerstin Linde, Dr Harald Blomberg and Moria Dempsey: Rhythmic RTM Training: http://www.rhythmicmovement.com/

- Masgutova -MNRI ® Method, Svetlana Masgutova: Neuro-sensory-motor reflex integration method http://masgutovamethod.com/

- $\quad$ Method Bobath. Berta Bobath: TNZ (Neuro-Developmental Treatment) http://www.ndta.org/ndt-certification.php

- Method Doman: Glenn Doman

- INPP Method: Peter Blythe and Sally Goddard-Blythe: http://www.inpp.org.uk/contact-us/inpp-licentiates/

\section{Bibliography:}

[1] Allen \& Capture, 1986; Zafeiriou, 2004; Sanders \& Gilling, 2011.

[2] Andermann, 1997; Franz dhe Gillett, 2011; Jacyna, 2011)

[3] Arnold, Clark, Sachs, Jakim, \& Smithies, 1985

[4] Arnsten, 2009; Shaw dhe Rabin , 2009; Makris et al, 2009)

[5] Ayres 1972/3, Bender 1976, Blythe McGlown 1979

[6] Bankat et al, 2003.); të përjetuara nga fëmijët me DCD (Ward \& S Rodger, 2004 Taylor et al, 1994.

[7] Barkley, 1997a; Houghton et al., 1999; Schachar, Mota, Logan, Tannock \& Klim, 2000.

[8] Bein-Wierzbinski, W. (2001). Persistent primitive reflexes in elementary school children. Effect on oculo-motor and visual perception. Paper presented at The 13th European Conference of Neuro-Developmental Delay in Children with Specific Learning Difficulties. Chester. UK.

[9] Bender 1976, O'Dell and Cook 1996, McPhillips et al.20001, The North Eastërn Education and Library Board Report 2004, Goddard Blythe 2005.

[10] Bender 1976, O'Dell dhe Cook 1996, McPhillips etj. al.20001, Arsim Lindore Veriut dhe Library Board Raport 2004, Goddard Blythe 2005.

[11] Bernw, S.A. (2006) Fawcett AJ, Nicolson RI, Dean P 1996.

[12] Berquin et al, 1998; Baillieux et al, 2008 ; Buderath et al, 2009 ; O'Halloran et al

[13] Blauw-Hospwrs et al, 2011; Hung \& Pang, 2010)

[14] Blauw-Hospwrs et al, 2011 ; Hung dhe Pang, 2010; Niemeijer et al, 2007; watemberg et al, 2007 ;

Schoemaker et al, 2003 ; Quigg, 2003 ; Lee dhe Smith, 2002 ; Leemrijse et al, 2000; Lee dhe G.Smith 1998).

[15] Blomberg. H and Dempsey. M. Movements that Heal.(2011).

[16] Blythe, 2005 ; McPhillips et al, 2000.

[17] Blythe, 2010; McPhillips \& Sheehy, 2004; Freides et al.,1980 
[18] Blythe, S. (2005) Releasing Educational Potential Through Movement: A Summary of Individual Studies Carried Out Using the INPP Test Battery and Developmental Exercise Programme for use in Schools with Children with Special Needs. Child Care in Practice, 11 (4), pp.415-432.

[19] Blythe, S. (2010) Neuro-motor Maturity as an Indicator of Developmental Readiness for Education. inpp.org.uk, pp.121-136.

[20] Bobath \& Bobath 1965, Ayres 1972/3, Fiorentino 1981, Levitt 1984.

[21] Buderath et al, 2009; D'Agati et al, 2010; Ghanizadeh, 2011

[22] Buderath et al, 2009; D'Agati et al, 2010;Ghanizadeh, 2011

[23] Cambier, Masson, Dehen. Neurology, Eurorilindja, Tiranë, 1996, faqe 39-85.

[24] Capute AJ, Shapiro BK, Palmer FB, Accardo PJ, Wachtel RC. Primitive reflexes: "A factor in nonverbal language in early infancy In": (Stark,ed) "Language behavior in infancy and early childhood". North Holland: Elsevier, 1981; 157-61).

[25] Capute, A. J, Palmer, F. B., Shapiro, B. K, Wachtwl, R. C, Ross, A, Accardo, P. J. (1982), Primitive reflex profile: A quantitation of primitive reflexes in infancy. Developmental Medicine and Child Neurology, 26, p. 375-383.

[26] Capute, A. J., Palmer, F. B., Shapiro, B. K., Wachtël, R. C., Ross, A., Accardo, P. J. (1982).

[27] Caputw AJ, Shapiro BK, Palmer FB, Accardo PJ, wachtël RC 1981.

[28] Clara Hannanaford,PH.D. Smart Movement. (1995), p. 96-107.

[29] Claudine Amiel-Tison.Neurological Evaluation of the Maturity of Newborn Infants.

[30] Continuity of neural Functions from Prenatal to Postural Life Fetal. Motolity in the first helf of pregnancy. P.4664) Internet:

[31] De Quirós dhe Schrager 1978, Kohen-Raz (1986).

[1] http://dx.doi.org/10.5014/ajot.2012.665001

[2] http://www.retainedneonatalreflexes.com.au/test-at-hom//

[3] http://www.wrightslaw.com/info/read.dysgraphia.facts.html

[4] www.adta.org

[5] www.inpp.org.ukk

[6] The Masgutova Neurosensorimotor Reflex Integration - MNRI ® Method, Svetlana Masgutova http://masgutovamethod.com/

[7] NDT (Neuro Developmental Treatment)- Bobath Method, Berta Bobath, http://www.ndta.org/ndtcertification.php

[8] INPP Method, Peter Blythe and Sally Goddard-Blythe: http://www.inpp.org.uk/contact-us/inpp-licentiates/

[9] Rhythmic Movement Training: Kerstin Linde, Dr Harald Blomberg and Moria Dempsey http://www.rhythmicmovement.com/

[10] Doman Method Glenn Doman: The Institutes for the Achievement of Human Potential, https://iahp.org/contactinfo 